\title{
Chitin-chitosan complex from Rhizopus oryzae obtained on a pea culture medium, and some of its physicochemical properties
}

\author{
Anna Beliaeva ${ }^{1, *}$, Galina Nianikova ${ }^{1}$, and Polina Rostovtseva ${ }^{1}$ \\ ${ }^{1}$ Saint-Petersburg State Institute of Technology, Microbiological Synthesis' Technology Department, \\ 190013, 26 Moskovsky prospect, St. Petersburg, Russia
}

\begin{abstract}
The article provides information about the way of obtaining chitin-chitosan biosorbents from the fungus Rhizopus oryzae, using mild deacetylation and demineralization conditions. Such physicochemical properties as deacetylation degree, total ash, weight loss on drying etc. were determined. Method of obtaining the chitin-chitosan complex, shown in the current study, allows to obtain a pure biosorbent with a high degree of deacetylation possible to be further used as entero- and hemosorbent.
\end{abstract}

\section{Introduction}

The Rhizopus oryzae fungus is able to produce a large number of valuable products: enzymes, lactic acid, antimicrobial drugs, ethanol, etc., therefore it is considered to be a promising object for scientific research and practical application. $R$. oryzae is nonpathogenic, contains no mycotoxins and is also used in food industry [1,2].

Rhizopus oryzae, belonging to the Zygomycetes class, contains chitin in its cell wall. Due to the presence of chitin deacetylase enzyme, $R$. oryzae synthesizes chitosan, which is an excellent sorbent with a high sorption capacity. Chitosan and its derivatives are used as sorbents for the elimination of radionuclides, heavy and transition metals, synthetic dyes, and pesticides [2-8].

The advantages of obtaining chitin and chitosan complexes from fungi include the constancy of the feedstock quality, the ability to control the cultivation conditions, a decrease in the final cost of sorbents, and the possibility of waste disposal due to the production of additional valuable products [9-10].

Compared to the most common source - crustaceans' shell - fungal sources of chitin and chitosan have a lot of of technological advantages: there is no need to grind raw materials and to remove calcium carbonate; it is possible to isolate the product using dilute acids and alkalis, which will lead to the formation of less waste that require a special disposal [11-12].

Chitosan has shown the ability to sorb medical preparations as well $[13,14]$. It can also be used to remove pharmaceuticals from human body in case of poisoning by the excessive intake of medical preparations. Due to the presence of hydroxyl and amino groups in its

*Corresponding author: belyaeva_any@mail.ru 
structure, chitin-chitosan complex obtained from Rhizopus oryzae is possible to be used as a specific sorbent for detoxification in procedures such as enterosorption, hemosorption, hemodialysis, hemofiltration, plasmapheresis, etc., and also, possibly, to enhance the sorption properties of other enterosorbents.

\section{Materials and methods}

The objects used in the current study were as following:

- Rhizopus oryzae fungus, deposited in the All-Russian collection of industrial microorganisms (VKPM) under the number F-814. According to the passport, it is a producer of $\mathrm{L}(+)$-lactic acid, $\alpha$-amylase and glucoamylase. The strain was maintained in the microorganisms' collection of the Microbiological Synthesis' Technology Department, St. Petersburg State Institute of Technology (TU) by periodic reseeding using the potatoglucose agarized culture medium;

- Rhizopus oryzae biomass obtained of the pea medium with additives;

- biosorbents (BS-1, BS-2, BS-3) obtained from Rhizopus oryzae biomass according to the scheme (Fig. 1).

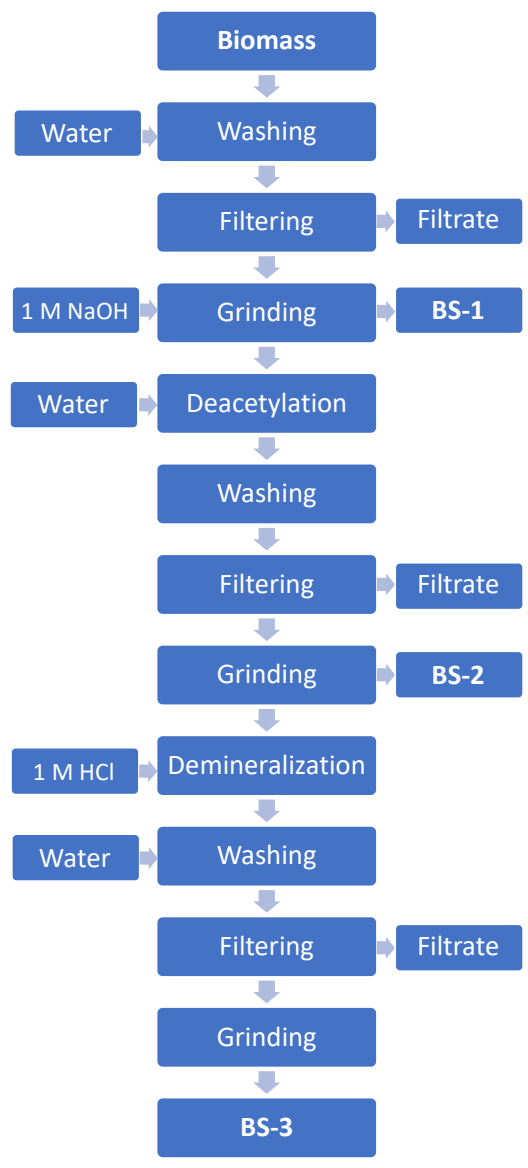

Fig. 1. Biosorbents' (BS-1, BS-2, BS-3) obtaining scheme.

During the experimental development of the conditions for isolation and purification of the chitin-chitosan complex, the culture liquid was filtered through a paper filter, then dried 
at a temperature of $50^{\circ} \mathrm{C}$ and crushed using a grinder (BS-1 biosorbent). A $1 \mathrm{M} \mathrm{NaOH}$ solution was added to the crushed biomass in the ratio of biomass $(\mathrm{g}): 1 \mathrm{M} \mathrm{NaOH}$ solution $\left(\mathrm{cm}^{3}\right)=1: 5$ and autoclaved for $30 \mathrm{~min}$ at a pressure of $101 \mathrm{kPa}$. The precipitate was washed with distilled water until a $\mathrm{pH}$ of 7 was reached. Centrifugation was carried out for $15 \mathrm{~min}$ at $83.33 \mathrm{~s}^{-1}$, after which the precipitate was dried to constant weight at a temperature of $50^{\circ} \mathrm{C}$ and grinded. As a result, a biosorbent designated BS-2 was obtained.

Part of BS-2 was left for further studies, and the other part was treated with constant stirring for $40 \mathrm{~min}$ with $1 \mathrm{M} \mathrm{HCl}$ solution in the ratio of biomass $(\mathrm{g}): 1 \mathrm{M} \mathrm{HCl}\left(\mathrm{cm}^{3}\right)=1: 5$ for activation. The precipitate was washed with distilled water until a $\mathrm{pH}$ of 7 was reached. Centrifugation was carried out for $15 \mathrm{~min}$ at $83.33 \mathrm{~s}^{-1}$, after which the precipitate was dried to constant weight at a temperature of $50^{\circ} \mathrm{C}$ and the grinded. As a result, an activated biosorbent, which was designated BS-3, was obtained.

\subsection{Culture medium preparation}

\subsubsection{Potato-glucose agar}

To the potato broth prepared using $200 \mathrm{~g}$ of potatoes per $1 \mathrm{~L}$ of water, $20 \mathrm{~g} / \mathrm{L}$ of agar and 20 $\mathrm{g} / \mathrm{L}$ of glucose were added and heated until the complete dissolution. Sterilization was held at $9,8 \cdot 10^{5} \mathrm{~Pa}$ during $30 \mathrm{~min}$.

\subsubsection{Pea medium with additives}

To the pea broth prepared using $50 \mathrm{~g}$ of peas per $1 \mathrm{~L}$ of water, $5 \mathrm{~g} / \mathrm{L}$ of glucose and $10 \mathrm{~g} / \mathrm{L}$ of ammonium sulfate were added and heated until the complete dissolution. Sterilization was held at $9,8 \cdot 10^{5} \mathrm{~Pa}$ during $30 \mathrm{~min}$.

\subsection{Rhizopus oryzae cultivation}

To obtain the inoculum museum culture of Rhizopus oryzae was subcultured into test tubes with a slant agar medium (potato-glucose agar) and incubated at $28^{\circ} \mathrm{C}$ for 5 days.

To prepare the inoculum $5 \mathrm{~mL}$ of sterile distilled water was added to the test tubes with slant agar medium and stirred a bit. The resulting inoculum was transferred into $750 \mathrm{~mL}$ Erlenmeyer flasks containing a fermentation medium (pea medium with additives) - 1 test tube for each of the Erlenmeyer flasks. Fermentation was carried out on a rocker unit with a rotation speed of $220 \mathrm{rpm}$ at a temperature of $28^{\circ} \mathrm{C}$ for 3 days, at a volume of $150 \mathrm{~mL}$.

At the end of the fermentation, the biomass was separated from the liquid phase by filtration through a paper filter on a Buchner funnel.

\subsection{Biomass and biosorbent analysis}

\subsubsection{Determination of the biomass quantity}

The filtered biomass was poured into pre-weighed Petri dishes, then dried to constant weight at a temperature of $50^{\circ} \mathrm{C}$ and reweighed.

The concentration of dry biomass was determined using formula 1:

$$
G=\frac{m}{V}
$$


where $\mathrm{G}$ - concentration of dry biomass, $\mathrm{g} / \mathrm{L}$;

$\mathrm{m}$ - mass of dry biomass, $\mathrm{g}$;

$\mathrm{V}-$ volume of culture liquid, $\mathrm{L}$.

\subsubsection{Determination of the total ash}

The determination of the total ash was carried out with a ground test samples according to the Russian State Pharmacopoeia XIV.

The dried samples were ground with a pestle and mortar to a particle size of no more than $2 \mathrm{~mm}$ (the sieve method was used to separate the test samples).

The porcelain melting pot was heated in a muffle furnace to red heat $\left(550-650^{\circ} \mathrm{C}\right)$ for 30 min, then cooled in a desiccator and accurately weighed. The melting pot was calcined to a constant weight. About $1 \mathrm{~g}$ (accurately weighed) of dried materials (BS-1, BS-2, BS-3) was placed in a prepared melting pot, evenly distributing the analyzed sample along its bottom. The test sample in the melting pot was carefully heated at $100-105^{\circ} \mathrm{C}$ for $1 \mathrm{~h}$, and then combusted, following by calcining the rest of the sample at a temperature of $550-650^{\circ} \mathrm{C}$. The melting pot was cooled in a desiccator and weighed. Calcination was repeated to the constant weight, avoiding ash fusion, and sintering with the crucible walls, avoiding the flame formation.

The total ash content $(\mathrm{X})$ in the samples in percent was calculated according to the formula 2:

$$
X=\frac{m_{1}}{m_{2}} \times 100 \%
$$

where $\mathrm{ml}$ - mass of ash, g;

$\mathrm{m} 2$ - mass of the sample, $\mathrm{g}$.

\subsubsection{Determination of the weight loss on drying}

The analysis was carried out according to the Russian State Pharmacopoeia XIV.

Samples were dried for 2 hours in a baker within the of $50{ }^{\circ} \mathrm{C}$. After that, the open weighing cup with its cover was placed in an exsiccator to cool down for 50 minutes, after which it is closed with the cover and weighed. Subsequent weighing procedures were performed once an hour during the subsequent weighing, until a constant weight is achieved.

$$
X=\frac{\left(m_{2}-m_{3}\right)}{\left(m_{2}-m_{1}\right)} \times 100 \%
$$

where $\mathrm{ml}$ - mass of the weighing cup brought to the constant mass, $\mathrm{g}$; $\mathrm{m} 2$ - mass of the weighing cup with the test sample before drying, $\mathrm{g}$;

$\mathrm{m} 3$ - mass of the weighing cup with the test sample after drying, g.

\subsubsection{Deacetylation degree determination}

The degree of deacetylation was determined by conductometric titration on an AT-50 automatic titrator manufactured by Mettler Toledo (serial number B311122583).

About $100 \mathrm{mg}$ (accurately weighed) of the dried test sample was suspended in $20 \mathrm{~mL}$ of $0.1 \mathrm{~N} \mathrm{HCl}$ and $80 \mathrm{~mL}$ of water with stirring using an electric stirrer of the AT-50 instrument for 15 minutes. In parallel, $0.5 \mathrm{~N} \mathrm{NaOH}$ was prepared in accordance with the requirements of the Russian State Pharmacopoeia XIV, the titer was established. The resulting solution was titrated with $0.5 \mathrm{~N} \mathrm{NaOH}$ in an automatic mode. 
Food chitosan was taken as a model sample to check the convergence of the obtained deacetylation degree values with the values from the manufacturer's passport - CJSC "BIOPROGRESS" (p.01 of 26.02.2006) - $88 \%$.

The degree of deacetylation was calculated using the formula 4 :

$$
D D=\frac{203 \times V \times N}{m}+42 \times V \times N
$$

where DD - degree of deacetylation, \%;

$\mathrm{V}$ - volume of $\mathrm{NaOH}$ determined from the conductometric titration graph, $\mathrm{mL}$;

$\mathrm{N}$ - alkali normality;

$\mathrm{m}-$ sample weight, $\mathrm{mg}$.

\subsection{5 $\mathrm{pH}$ determination}

The hydrogen index was determined in accordance with TU 9289-067-00472124-03 - in a $1 \%$ solution of the sample in $2 \%$ acetic acid.

A $2 \%$ acetic acid solution was prepared. $1 \mathrm{~g}$ of a sample (accurately weighed) was placed in a $100 \mathrm{~mL}$ flask, dissolved in $50 \mathrm{~mL}$ of $2 \%$ acetic acid, brought to the mark with the same solvent, and mixed. The $\mathrm{pH}$ was determined potentiometrically using Seven S470 combined meter manufactured by Mettler Toledo (serial number B244466998).

\section{Results and discussion}

It was found before [15] that the largest amount of biomass of the fungus $R$. oryzae provides the culture media of the following composition, $\mathrm{g} / \mathrm{L}$ : pea - 50; glucose - 5.0; $\left(\mathrm{NH}_{4}\right)_{2} \mathrm{SO}_{4}-10.0$, the maximum biomass concentration is reached on the third day of cultivation.

Biosorbents BS-1, BS-2 and BS-3 were obtained according to the scheme on Fig.1.

It is vital to notice that traditionally chitosan is obtained by deacetylation, including long-term (up to 6 hours) treatment with alkali when heated to temperatures of $110-140^{\circ} \mathrm{C}$ [2]. However, since Rhizopus oryzae directly contains chitosan in its cell wall, which can easily be isolated, avoiding the costly and unsafe deacetylation step, it is advisable to study the need for heating or, if necessary, the possibility of heating for a much shorter time.

Obtaining the BS-2 using mild deacetylation leaded to the increasing of deacetylation degree from $22,83 \%$ in BS-1 to $86,75 \%$ in BS-2 as shown in Table 1.

Also, due to autoclaving, additional disinfection of the biomass is carried out, together with deproteinization and deacetylation under mild conditions.

Table 1. Results of deacetylation degree determination.

\begin{tabular}{|c|c|c|c|c|}
\hline \multirow{2}{*}{ Sample } & \multicolumn{4}{|c|}{ Results $(\mathrm{k}=1.0004 \rightarrow 0.5002 \mathrm{~N} \mathrm{NaOH})$} \\
\hline & $m, \mathrm{~g}$ & $V, \mathrm{~mL}$ & $\mathrm{DD}, \%$ & $\mathrm{DD}_{\text {average }}, \%$ \\
\hline \multirow{2}{*}{ BS-1 } & 100.0096 & 1.078 & 23.75 & \multirow{2}{*}{$22.83 \pm 1.31$} \\
\hline & 100.0744 & 0.994 & 21.90 & \\
\hline \multirow{2}{*}{ BS-2 } & 100.0785 & 3.983 & 85.55 & \multirow{2}{*}{$86.75 \pm 1.70$} \\
\hline & 100.1028 & 4.004 & 87.95 & \\
\hline \multirow{2}{*}{ Food chitosan } & 100.0085 & 4.002 & 88.17 & \multirow{2}{*}{$89.01 \pm 1.18$} \\
\hline & 100.0266 & 4.016 & 89.84 & \\
\hline
\end{tabular}


BS-2 yield amounted approximately to $80 \%$ of BS- 1 . Despite the fact that the product yield is not too high, the removal of inhomogeneous components of the biomass and obtaining a product with a high degree of deacetylation will make it possible to conclude that the characteristics of the product are comparable to crab chitosan.

In order to increase the sorption capacity of the obtained biosorbent (BS-2), the acid activation (demineralization) was carried out. The yield of biosorbent (BS-3) after demineralization amounted to $18 \%$ of BS- 1 .

The results obtained when determining the total ash are shown in Table 2.

Table 2. Results of total ash quantity in biosorbents.

\begin{tabular}{|l|c|c|c|c|}
\hline \multirow{2}{*}{ Sample } & \multicolumn{4}{|c|}{ Total ash results } \\
\cline { 2 - 4 } & $m_{1}, \mathrm{~g}$ & $m_{2}, \mathrm{~g}$ & $\mathrm{X}, \%$ & $\mathrm{X}_{\text {average }} \%$ \\
\hline \multirow{2}{*}{ BS-1 } & 0.1429 & 1.0124 & 14.12 & \multirow{2}{*}{$14.26 \pm 0.20$} \\
\cline { 2 - 4 } & 0.1490 & 1.0342 & 14.40 & \\
\hline \multirow{2}{*}{ BS-2 } & 0.0519 & 1.0067 & 5.16 & \multirow{2}{*}{$5.43 \pm 0.27$} \\
\cline { 2 - 4 } & 0.0578 & 1.0143 & 5.70 & \\
\hline \multirow{2}{*}{ BS-3 } & 0.0074 & 0.9999 & 0.74 & \multirow{2}{*}{$0.77 \pm 0.03$} \\
\cline { 2 - 4 } & 0.0081 & 1.0174 & 0.80 & \\
\hline
\end{tabular}

As shown in Table 2, the amount of total ash decreases from BS-1 to BS-2 and from BS-2 to BS-3. The purer the biosorbents become - the less total ash was found in the samples. Both deacetylation and demineralization lead to purifying the sorbent, leading to no need in further additional purification of BS-3.

When studying the weight loss on drying, it was determined that the average tends to be is around $8 \%$ for all 3 biosorbents obtained (Table 3 ).

Table 3. Weight of loss on drying BS-1, BS-2 and BS-3.

\begin{tabular}{|l|c|c|c|c|c|}
\hline \multirow{2}{*}{ Sample } & \multicolumn{5}{|c|}{ Weight of loss on drying the biosorbents } \\
\cline { 2 - 5 } & $m_{l, g}$ & $m_{2}, g$ & $m_{s}, g$ & $\mathrm{X}, \%$ & \multirow{2}{*}{$\mathrm{X}_{\text {average, } \%}$} \\
\hline \multirow{3}{*}{ BS-1 } & 20.1536 & 25.2379 & 24.8475 & 7.68 & \multirow{2}{*}{$7.52 \pm 0.23$} \\
\cline { 2 - 5 } & 21.2247 & 26.3746 & 25.9963 & 7.35 & \\
\hline \multirow{3}{*}{ BS-2 } & 19.7468 & 24.8719 & 24.5063 & 7.13 & \multirow{2}{*}{$7.65 \pm 0.74$} \\
\cline { 2 - 5 } & 21.4197 & 26.5574 & 26.1375 & 8.17 & \\
\hline \multirow{2}{*}{ BS-3 } & 22.8675 & 28.1567 & 27.7427 & 7.83 & \multirow{2}{*}{$7.99 \pm 0.22$} \\
\cline { 2 - 5 } & 21.0994 & 26.2863 & 25.884 & 7.76 & \\
\hline
\end{tabular}

All the results for weight of loss on drying obtained for biosorbents BS-1, BS-2 and BS3 respond the TU 9289-067-00472124-03 for chitosan.

$1 \%$ solutions of BS-1, BS-2 and BS-3 in $2 \%$ acetic acid showed respectively the following $\mathrm{pH}$ value of $4.42 \pm 0.06,4.62 \pm 0.05$, and $3.91 \pm 0.05$.

\section{Conclusion}

The studies carried out made it possible to obtain chitin-chitosan biosorbents from the fungus Rhizopus oryzae, using a cheap and available substrate - pea medium with additives. The main advantage of current technology for producing fungal chitosan in comparison with chitosan from shell-containing raw materials is standardized cultivation 
conditions in a controlled mode. As a result, the biosorbent has homogeneous composition and stable properties. The stages of deacetylation and demineralization of chitin-chitosan complex obtained from $R$. oryzae are carried out in milder conditions than that of crustacean chitosan, and do not require high energy consumption.

Mild deacetylation shows a significant effect on the increasing the biosorbent's deacetylation degree by elimination the additional amino groups. As a result, it will positively affect the sorption properties of the sorbent. Also, this type of deacetylation, being cheap and easy to implement, reduces total cost of the product. Deminirealization plays an important role in purifying and activating the sorbent, leading to reducing the amount of outsider impurities and to increasing the sorption activity as well.

Thus, the alkali-insoluble part of the biomass can be used as a biosorbent either directly (BS-2) or after the acid activation stage (BS-3).

The output of BS-2 was $81 \%$ of the initial biomass (BS-1), and BS-3 $-18 \%$ of the initial biomass.

When using the developed technology for the production of enterosorbent, it is possible to obtain a line of drugs that can be recommended in various fields, which will ensure the diversification of production in order to reduce economic risks.

Both BS-2 and BS-3 can be considered as candidate biosorbents for veterinary needs and for water purifying needs; the final biosorbent - BS-3 can also be considered as a candidate biosorbent for needs of entero- and hemosorption and will be studied futher.

\section{References}

1. M. Rinaudo, Progress in polymer science 31 (7), 603-632 (2006)

2. G.G. Niankova, S.M. Komissarchik, M.A. Vasioshenkova, K.V. Molchanova, D.A. Sokolova, T.E. Mametnabiev, News of SPbSIT (TU) 29 (55), 61-65 (2015)

3. K. Azlan, W.N.W. Saime, L.A. Liew, Journal of Environmental Sciences 21 (3), 296302 (2009)

4. J. Kucera, Journal of Chromatography B. 808, 69-73 (2004)

5. G.S. Rosa, M.A. Moraes, L.A. Pinto, LWT-Food Science and Technology 43 (3), 415 420 (2010)

6. E. Metwally, S.S. Elkholy, H.A.M. Salem, M.Z. Elsabee, Carbohydrate polymers 76 (4), 622-631 (2009)

7. V. Rungsardthong, N. Wongvuttanakul, N. Kongpien, P. Chotiwaranon, Process Biochemistry 41, 589-593 (2006)

8. G.G. Nianikova, T.E. Mametnabiev, Beverage industry 2, 90-94 (2007)

9. F. Tajdini, M.A. Amini, N. Nafissi-Varcheh, M.A. Faramarzi, International journal of biological macromolecules 47 (2), 180-183 (2010)

10. M.T. Yen, J.L. Mau, LWT-Food Science and Technology 40 (3), 472-479 (2007)

11. W.P. Wang, Y.M. Du, X.Y. Wang, World Journal of Microbiology and Biotechnology 24 (11), 2717-2720 (2008)

12. E.P. Feofilova, D.V. Nemtsev, V.M. Tereshina, A.S. Memorskaya, Applied Biochemistry and Microbiology 42 (6), 545-549 (2006)

13. Y. Zhang, Z. Shen, C. Dai, X. Zhou, Environmental Science and Pollution Research 21 (22), 12780-12789 (2014)

14. S. Zhang, Y. Dong, Z. Yang, W. Yang, J. Wu, C. Dong, Chemical Engineering Journal 304, 325-334 (2016) 
15. A.D. Beliaeva, A.A. Minina, P.A. Rostovtseva, G.G. Nianikova, Food technology and biotechnology 3, 264-268 (2019) 